\title{
Research on the Survival Strategy of SMEs under COVID-19--Based on the Perspective of Organizational Resilience
}

\author{
Xiaolin $\mathrm{Fu}^{*}$ \\ School of Accounting, Shandong Technology and Business University, Yantai, Shandong264000, China \\ *Corresponding author. Email:1210948102@qq.com
}

\begin{abstract}
A novel coronavirus has swept the globe in 2020. As the backbone of China's economic development, small and medium-sized enterprises (SMEs) are faced with many threats, and their economic activities are negatively affected. Based on the perspective of Organizational Resilience, the paper analyses the internal reasons why SMEs are difficult to deal with sudden disasters from their own development. Then, SMEs should seize the opportunity of new business policy and establish long-term resilience strategy to enhance organizational resilience and promote enterprise transformation, so as to achieve the purpose of adapting to environmental changes and enhancing survival ability. It is of practical significance to study the survival strategies of SMEs.
\end{abstract}

Keywords: Survival strategy, organizational resilience, SMEs

\section{INTRODUCTION}

By the end of 2018, there were about 30 million SMEs in China. In the development of national economy, about $50 \%$ of the tax revenue, more than $60 \%$ of the GDP, and more than $80 \%$ of the urban labor force employment have been created [1]. As an important part of China's real economy, the living conditions of small and medium-sized enterprises (SMEs) will affect the stable development of economy. Under the influence of COVID-19, SMEs face both threats and opportunities. The main reason affecting the survival ability of SMEs is that their survival mechanism is not perfect. Based on the perspective of organizational resilience, this paper provides ideas for improving the "resilience" viability of SMEs in China, and looking for countermeasures to maintain the ability of development.

In the 1970s, the concept of "resilience" in physics was combined with the field of enterprise management [2]. After 1990, the concept of "Organizational Resilience" came into being. The study of organizational resilience is used to ensure rapid response and sustainable development of enterprises in uncertain environments [3]. By mapping the concept of resilience into the field of business management, can judge the development status of enterprises. In the past, the research focus of Organizational Resilience is to keep the enterprise adapt to the change of market environment [4]. With the changing environment, the types and conditions of organizational change risk become more and more diverse, which leads to the focus of Organizational Resilience research to focus on the ability of the organization to resist system disruption and adapt to new risks [5]. Organizational types are not only limited to SMEs, but also include enterprise systems and public welfare organizations [6]. Although the research elements and categories are more and more abundant, the core of Organizational Resilience research is still how to start the "effective response" mechanism to help organizations "maintain positive adjustment in challenging situations" and then develop continuously [7]. In addition to the risk or disturbance event itself, the factors that affect organizational resilience involve organizational resources, leadership behavior, organizational culture and social network, and interact with many factors, such as internal and external environment, dynamic capabilities, formal and informal connections [8]. The core meaning of resilience comes from two aspects of structure and process, thus the influencing factors of Organizational Resilience are related to the elements of organizational structure and process [9]. The improvement of organizational resilience covers the cycle and iteration process from "Identify changes in external environment - identifying key vulnerabilities taking effective actions"[10]. The purpose of the paper is to introduce the concept of organizational resilience, and analyse the internal development loopholes of the enterprise according to the threats of external environment to SMEs. Systematically integrate feedback information by summarizing, reflecting, learning and other behaviors, adjusting the state of the enterprise to actively meet challenges. Then optimizing the organizational resilience structure of the enterprise, improving the ability to identify risks and resource integration, and play a role in enhancing environmental adaptability. It provides a reference for cultivating the resilience of Chinese SMEs in response to sudden disasters, which will enhance the enterprise's environmental adaptability. 


\section{IDENTIFY CHANGES IN EXTERNAL ENVIRONMENT--THE THREAT OF EPIDEMIC FOR SMES}

To some extent, the epidemic is "external shock", and the sudden change of environment disrupts the strategic planning of enterprises. In the complex economic situation, SMEs are facing the threat of force majeure in different degrees. The force majeure affecting the survival and development of SMEs can be divided into natural force majeure and social force majeure: natural force majeure includes earthquake, regional flood, etc.; social force majeure includes economic crisis, financial crisis, local war, government ban, public health crisis, etc. In fact, the outbreak of natural force majeure will lead to different degrees of social force majeure crisis, which aggravates the deterioration of market environment faced by SMEs [11].

The spread of the epidemic led to the global industrial chain on the verge of disruption and severe foreign trade situation. China's foreign demand decreased by $30 \%$ yearon-year [12], which has a negative impact on enterprises' production and circulation, production capacity cooperation, overseas investment and other economic activities. Although SMEs' ratio of return to work has increased steadily, the income is on a cliff decline. The high cost and the low consumption demand lead to the lack of enthusiasm for the resumption of production. Many SMEs have difficulties in sustainable operation. According to the research conducted by Tsinghua Institute of Economic and Management, since the outbreak of the epidemic, about $85 \%$ of SMEs couldn't support operation for three months [13]. Moreover, SMEs are insensitive to relevant national and industrial policies and laws. Changes in policies and regulations also threaten the survival of enterprises.

\section{IDENTIFYING KEY VULNERABILITIES--THE REASONS FOR THE DIFFICULTIES IN THE SURVIVAL OF SMES}

\subsection{Pressure on the Supply Chain of SMEs is Increasing, Lack of Funds for Transformation}

SMEs have a traditional business mode and a single supply chain structure, which mainly rely on physical production and offline sales. In order to achieve the purpose of epidemic prevention and control, the delayed resumption of production policy has led to the untimely supply of raw materials and products that cannot be released in time. Expenses such as employee salaries, loan repayments and factory rents have increased the pressure on working capital turnover, and the risk of capital chain rupture has increased sharply [12].In this epidemic, most of the upstream enterprises in the supply chain choose to extend the accounting period. Once the capital chain of SMEs in the supply chain breaks, it is difficult to recover quickly in a short period of time.

SMEs have small amount of funds and poor resources, so it is difficult to obtain valuable project information to use, and the degree of transformation is difficult to grasp. The financing system of SMEs is difficult to promote the development of the company. For example, in the financing institutions, ordinary financing institutions are for state-owned or joint-stock companies with long-term financing experience, and there are few financing institutions for SMEs; in terms of financing funds, it is difficult for SMEs to provide collateral of the same value to obtain loans, and such enterprises are easy to go bankrupt, resulting in their inability to achieve the purpose of financing [14].

Most managers of SMEs are satisfied with the status quo, and their cognition of enterprise transformation remains at the initial level. They lack the knowledge of digital transformation and transformation ability. They usually do not have independent digital infrastructure or platform, lack of unified architecture platform, lack of agile development and personalized development of IT applications, data link hasn't been built, data processing capacity is limited, and lack of skilled personnel, there are no corresponding departments or teams to meet the needs of digitization [15].

\subsection{Lack of Organizational Resilience and Risk Control}

Although SMEs are easy to manage, quick to respond, and highly flexible, their disadvantages are particularly prominent. The management system of SMEs in China is chaotic and unreasonable, and lack of standardized decision-making institutions and procedures. The characteristics of SMEs are the internal factors that restrict the improvement of Organizational Resilience: there are a large number of SMEs, lack of industry barriers, and fierce competition in the market; products are mostly concentrated in labor-intensive industries and weak comprehensive strength; limited by technical level, the added value of products is low; the enterprise is small in scale, the retention rate of talents is low, and the flow of personnel is frequent; extensive management methods lead to single information channels and lack of mastery of core competitiveness[14]; SMEs lack soft power construction and ignore the importance of corporate culture; short life cycle and weak organizational resilience of enterprises are insufficient to accommodate risks.

SMEs are used to designing organizational development mode according to industry experience and their own core business, and only pay attention to scale growth and competition in the industry. However, this development mode is realized under the condition of continuity and linearity. This epidemic proves that the market environment in which enterprises live is uncertain, the risks are difficult to predict, and breakpoints are the basic 
form of market environment [16]. Managers of SMEs lack the awareness of risk management. In order to fully evaluate the project, they often rush to recover the cost after investment, and lack of macro-level research on the industry and international market. Even if the enterprise has a risk management system, it is often superficial. There is no plan and response measures for all kinds of risks that may exist in the process of operation. Once there is a crisis, it can only wait for death.

\section{TAKE EFFECTIVE ACTION-- MEASURES TO ENHANCE THE VIABILITY OF SMES}

\subsection{Grasp the New Business Policy, Promote Enterprise Transformation}

In January 2020, the "Regulations on Optimizing the Business Environment" formulated by the government began to be implemented. The business market environment is complex and changeable. Although the government has issued relevant policies to support SMEs, SMEs should also take the initiative to cater to the changing trend of the macro environment, adapt to the changes of the market and make response as soon as possible. In the initial stage of transformation, SMEs shouldn't unilaterally pursue the comprehensiveness and timeliness of corporate culture. They should base themselves on their actual conditions and combine the characteristics of the market, the needs of target consumer groups, the company's long-term strategy, and their main business to build up corporate values. Create a distinctive corporate image, and maintain differentiation from other entities in the economic market. SMEs can learn from benchmark companies in the same industry, accumulate experience, and lay the tone of corporate culture.

In the process of transformation of SMEs, the first thing is to optimize the organizational structure. The organizational structure of enterprises can comprehensively reflect whether the resources are reasonably allocated and whether the work content is consistent with the strategic objectives. Scientific organizational structure can effectively enhance the operational efficiency of enterprises. In order to meet the requirements of strategic changes, SMEs need to overturn the original organizational structure, re-evaluate the internal resources and capabilities, and restructure the organizational structure according to the new business needs. The adjustment of corporate organizational structure includes all-round reforms of corporate organizational forms, personnel structure, labormanagement relations, and information management. Ensure that after the transformation, the enterprise can maintain efficient operation efficiency and improve product quality while controlling operating costs. Choose a suitable strategic development model to promote the transformation of the enterprise, and finally realize the coordinated development of the transformation of the enterprise and the adjustment of the organizational structure.

\subsection{Enhance Organizational Resilience of Enterprises and Establish Long-Term Resilience Strategy}

The organizational structure of an enterprise is the external form of the enterprise. In the complex and changeable market environment, the negative impact will be very significant if managers only focus on the rigid process and authority. Managers can strengthen organizational resilience and build long-term resilience strategies by changing organizational management and working patterns. SMEs need to reflect on the defects in organizational management, cultivate managers with leadership, break the fixed process management mode, adjust the strategic direction in time according to market changes, and combine the risk control plan of each department with the overall development strategy of the company. One of the effective strategies to strengthen the organizational resilience is to change the organizational management mode. It is not only necessary to build the organizational emergency management system and enhance the risk perception ability, but also to change the organizational management mode according to the changes in the market environment and improve the organizational flexibility. Some authorities should be released appropriately to improve the response ability of each department to the epidemic, and ensure that employees can accurately understand the crisis faced by the company, and agree with the organizational risk management measures, so as to ensure that the risk strategy can be implemented in place, shorten the response time, and achieve the purpose of obtaining enterprise survival space.

Enterprises with value relationship networks, collaborative work platforms and core value partners can quickly respond to the impact of the epidemic, adjust their business behaviors to seize the opportunity, and make good achievements under the threat of global epidemic. Indicating that in the uncertain environment, competitors shouldn't be limited to the members of the same industry, and the development mode of the organization shouldn't be limited to scale expansion. The development mode should move from competition to symbiosis, from scale expansion to value growth, from investment driven to innovation driven. SMEs can establish dual business development mode, cooperate with core value partners inside and outside the industry, innovate value space, expand value boundary, and achieve the purpose of symbiosis with uncertainty. Intelligent collaborative work mode can effectively improve the organizational efficiency. Cooperating with core value partners in the organizational value relationship network can enhance the creativity of organizational members. This new mode can make SMEs dynamically respond to market changes, resist uncertainty risks jointly, and strengthen organizational resilience [13]. 


\section{CONCLUSION}

SMEs play an irreplaceable role in China's social and economic development, and have made outstanding contributions in social employment, tax contributions, technological innovation and other aspects. The spread of COVID-19 poses a challenge to the survival and development of SMEs. Adapting to the turbulent and uncertain environment as soon as possible and seeking countermeasures should become essential skills for SMEs. The purpose of introducing organizational resilience is to identify various factors that affect organizational resilience, summarize the deficiencies in the organizational structure, corporate culture, and managerial behavior of SMEs in responding to the epidemic, so as to find a scientific path to improve organizational resilience, seize opportunities for transformation, optimize organizational structure, build a value relationship network, and restore production and operation capabilities as soon as possible. Transform sudden risk management into normalized strategic management, adapt to the complex and changeable market environment, and provide reference ideas for SMEs in China to fundamentally solve the current situation of difficult survival.

\section{REFERENCES}

[1] Jun Li, Ministry of Industry and Information Technology: As of the end of last year, the number of SMEs in China has exceeded 30 million [DB/OL], http://www.chinanews.com/gn/2019/09-

20/8961119.shtml, 2019-09 -20/2020-07-31.

[2] Yuxin Lan, Community Resilience: A New Proposition for Grassroots Governance System and Capacity Modernization [J], China Non-profit Review, 25(01) (2020) 25-28.

[3] Shubo Liu, Organizational resilience: the ability to grow in a crisis $[\mathrm{J}]$, Tsinghua Management Review, (06) (2020) 90-95.

[4] Mallak L, Putting organizational resilience to work [J], Industrial Management, 40(6) (1998) 8-13.

[5] Stephen C, Danneth A, Scotte B, et al, General resilience to cope with extreme events[J], Sustainability, 4(12) (2012) 3248-3259.

[6] Witmer H, Mellinger M S, Organizational resilience: Nonprofit organizations' response to change [J], Work, 54(2) (2016) 255-265.

[7] Vogus T J, Sutcliffe K M, Organizational resilience: towards a theory and research agenda[C]//IEEE International Conference on System, Man and Cybernetics, Canada, IEEE, 2007.
[8] Min Tang, Shiming Li, Bin Liu, Organizational resilience and its evolution in the context of sudden disasters: A case study of Dongfang Steam Turbine Co., Ltd.'s response to the "5.12" Wenchuan earthquake and recovery and reconstruction $[\mathrm{J}]$, Techno-economics, 38(01) (2019) 28-37.

[9] Yan Wang, Haibo Zhang, Disaster resilience: definition, dimensions and measurement [J], Risk and Disaster Crisis Research, (01) (2017) 37-51.

[10] Sonia McManus, Erica Seville, John Vargo, Facilitated Process for Improving Organizational Resilience [J], Natural Hazards Review, 9(2) (2008) 8190 .

[11] Wenjie Ouyang, Minfeng Lu, Research on the resilience and elasticity of small and medium-sized enterprises under COVID-19--Based on the survival perspective of small and medium-sized enterprises under the background of force majeure [J], Journal of Changchun Finance College, (02) (2020) 75-86.

[12] Yude Xu, Challenges faced by small and mediumsized enterprises under the impact of the global epidemic and countermeasures $[\mathrm{J}]$, Finance and Accounting Monthly, (12) (2020) 114-118.

[13] Xiu Yang, Chulong Zhao, Research on organizational resilience construction of SMEs under the background of emergency management [J], Journal of University of Science and Technology Beijing (Social Science Edition), 36(03) (2020) 48-54.

[14] Fang Cui, Discussion on the transformation and development of China's SMEs in the new business environment $[\mathrm{J}]$, Business Economics Research, (11) (2020) 147-150.

[15] Wei Li, Wenjun Li, Looking at the digital transformation of SMEs from the prevention and control of the new crown pneumonia epidemic [J], Enterprise Economy, (07) (2020) 14-19.

[16] Frederick Funston, Stephen Wagner, Surviving and thriving in uncertainty: creating the risk intelligent enterprise [M], Deloitte China Enterprise Risk Management Service Department, Shanghai: Shanghai Jiaotong University Press, 2015. 